\title{
Hidden 19S IgM rheumatoid factor in adults with juvenile rheumatoid arthritis onset
}

\author{
JAMES C SPEISER, TERRY L MOORE, TERRY D WEISS, \\ ANDREW R BALDASSARE, STEPHEN C ROSS, THOMAS G OSBORN, \\ ROBERT W DORNER, AND JACK ZUCKNER
}

From the Division of Rheumatology, Departments of Internal Medicine and Pediatric-Adolescent Medicine, St Louis University School of Medicine, St Louis, MO 63104, USA

SUMMARY Forty-eight adult patients with juvenile rheumatoid arthritis (JRA) (onset before age 16 years) were evaluated at the age of 17 years or more for the presence of hidden 19S IgM $\stackrel{\circ}{\oplus}$ rheumatoid factors (RF), i.e., 19S IgM RF that can be detected by the complement-dependent $\mathrm{O}$ haemolytic assay in the IgM-containing fraction after separation of the serum by acid gel $\rightarrow$ filtration. The average age of the patients was $25 \cdot 3$ years. The mean duration of disease was $16 \cdot 5 \frac{3}{\mathrm{~N}}$ years. Thirty-two of 48 patients $(67 \%)$ showed the presence of hidden 19S IgM RF in their serum. Disease activity correlated with hidden RF titres in $62 \%(55 / 88)$ of the evaluations. The results indicate that patients with seronegative JRA onset continue to have significant titres of hidden O) 19S IgM RF in their sera into early adulthood.

Key-word: seronegative rheumatoid arthritis.

Classical 19S IgM rheumatoid factors (RF) as detected by the latex fixation test (LFT) are usually found in the sera of only $5-10 \%$ of cases of children with juvenile rheumatoid arthritis (JRA) ${ }^{1}$ as compared with $80 \%$ of adults with rheumatoid arthritis (RA). ${ }^{2}$ Hidden 19S IgM RF, i.e., 19S IgM RF detected in the IgM-containing fraction of serum after separation by acid gel filtration, were initially described by Allen and Kunkel ${ }^{3}$ in adults with severe RA who were seronegative for 19S IgM RF by the LFT. Moore et $a l .{ }^{4}$ first showed the presence of hidden 19S IgM RF in children with JRA. They found these RF by means of the LFT in $46 \%$ of seronegative JRA patients. Moore et al. ${ }^{56}$ found hidden RF in $59-68 \%$ of children with seronegative JRA by the complement-dependent haemolytic assay for detection of RF. Thus hidden RF as determined by the haemolytic assay or by the LFT could be shown to be present in approximately $75 \%$ of children with JRA. In a longitudinal study hidden 19S IgM RF correlated strongly with disease activity in JRA patients. ${ }^{7}$

The present study was undertaken to determine

Accepted for publication 13 November 1984.

Correspondence to Dr T L Moore, Associate Professor of Internal Medicine and Pediatrics-Adolescent Medicine, Director, Division of Rheumatology, St Louis University School of Medicine, R215 Doisy Hall, 1402 South Grand Boulevard, St Louis, MO 63104, USA. whether hidden 19S IgM RF were still present in the sera of JRA patients who reached young adulthood. $\overrightarrow{\overrightarrow{0}}$ The relationship of these hidden $\mathrm{RF}$ to disease activity and duration of disease was also evaluated.

Materials and methods

PATIENTS

Sera were obtained from 48 adult $(\geq 17 \text { years of age })^{2}$ patients who had a diagnosis of JRA made before they were 16-years old by criteria established by the Committee on the Classification of JRA of the American Rheumatism Association. ${ }^{8}$ Sera were also obtained from 65 children, 35 healthy and 30 . patients with connective tissue disease (CTD), and from 50 adults, 25 healthy and 25 with CTD, to act as controls. The CTD controls were mainly patients with systemic lupus erythematosus, mixed connective tissue disease, progressive systemic sclerosis polymyositis, seronegative spondyloarthropathies and other related CTD. All specimens were drawn in clot tubes and allowed to clot for $\mathbf{3 0}$ minutes at room temperature. Sera were obtained by centri-군 fugation at $4^{\circ} \mathrm{C}$ and stored at $-70^{\circ} \mathrm{C}$ until tested $\stackrel{\vec{D}}{\circ}$ The 48 patients were attending the Arthritis Clinic? at St Louis University Medical Center or the private offices of Division rheumatologists. 79\% (38/48) had been under our observation both as children and as? 
adults; the remaining $21 \%$ had been followed up elsewhere before adulthood. Age range at the time of evaluation was $18-38$ years; mean age $25 \cdot 3$ years. The method for determining disease activity was established before the onset of the study and activity of disease was assessed at the time of each evaluation. Active disease was defined on a two point scale: $(-)$ indicated no active joint disease; and (+) indicated one or more swollen painful joints.

\section{HAEMOLYTIC ASSAY}

Sera were subjected to acid gel filtration on a Sephadex G-200 column $(2.5 \times 85 \mathrm{~cm})$ essentially by the method of Allen and Kunkel, as previously described. ${ }^{3}$ The IgM and IgG fractions were concentrated to the original serum volume by vacuum dialysis. Purity of fractions was determined by immunodiffusion against rabbit antihuman IgG, IgA, and IgM (Behring Diagnostics, Somerville, $\mathrm{NJ})$. The sera and IgM and IgG fractions were then heat inactivated at $56^{\circ} \mathrm{C}$ for 30 minutes and absorbed by washed sheep red blood cells (SRBC) (Alban Co., St Louis, MO) for 90 minutes at $37^{\circ} \mathrm{C}$. A haemolytic assay was then carried out on the serum, $\mathrm{IgM}$, and IgG fractions, as previously described in detail $^{6}$ : $0 \cdot 1 \mathrm{ml}$ of serum, IgM, or IgG fractions was serially diluted in $0.1 \mathrm{ml}$ of $0.15 \mathrm{M}$ veronal-buffered saline containing $0.1 \%$ gelatin, $0.005 \mathrm{M} \mathrm{MgCl}_{2}$, and $0.00015 \mathrm{M} \mathrm{CaCl}_{2}$ at $\mathrm{pH} 7.4$ (GVB). $0.1 \mathrm{ml}$ of $1 \%$ sensitised SRBC was added to each dilution. The target cell SRBC were sensitised with a 1:100 dilution of rabbit anti-SRBC IgG haemolysin (Colorado Serum, Denver, CO), as previously described. ${ }^{56}$ After incubation at $37^{\circ} \mathrm{C}$ for 60 minutes and at $4^{\circ} \mathrm{C}$ for 60 minutes or overnight the cells were washed with $1 \mathrm{ml}$ of cold GVB and centrifuged at $4^{\circ} \mathrm{C}$ at $2000 \mathrm{rpm}$; the supernatant was discarded. $1 \mathrm{ml}$ of GVB and $0.4 \mathrm{ml}$ of 1:40 diluted guinea pig serum (Pel-Freez Co., Helena, AR) were added to the target cells. Guinea pig serum previously absorbed by SRBC was a source of complement. After incubation for 60 minutes at $37^{\circ} \mathrm{C}$ with vortexing every 15 minutes the reaction was stopped by addition of $1.5 \mathrm{ml}$ of cold $0.15 \mathrm{M}$ phosphate-buffered saline (PBS), $\mathrm{pH} 7 \cdot 3$. The tubes were centrifuged for 5 minutes at $4^{\circ} \mathrm{C}$ at $2000 \mathrm{rpm}$. Haemoglobin released into the supernatant was assayed spectrophotometrically at $412 \mathrm{~nm}$. Buffer and serum background controls and $100 \%$ water haemolysis controls were included in all assays. Titres for RF $>1: 16$ on the serum, IgM-, or IgGcontaining fractions were considered positive, since that titre differs significantly from the titre for age-matched healthy controls, children with systemic lupus erythematosus, polymyositis, etc., and from the titre for children with other illnesses. ${ }^{5}$
LATEX FIXATION TEST (LFT)

The LFT was performed on the whole serum after heat inactivation for 30 minutes at $56^{\circ} \mathrm{C}$ by the method of Singer and Plotz ${ }^{9}$ with a commercial test kit (Difco Laboratories, Detroit, MI). Titres greater than 1:20 were considered positive.

ANTINUCLEAR ANTIBODIES (ANA)

ANA were determined by indirect immunofluorescence on sections using mouse kidney or human epithelial (HEp-2) cells as substrate and fluoresceinlabelled antihuman IgG or IgM antibody. Titres $>1: 20$ were considered positive.

\section{Results}

Data on the patients' clinical findings are summarised in Table 1. Results of testing for 19S IgM RF, hidden 19S IgM RF, and ANA are also tabulated.

Six men and 42 women with JRA diagnosed in childhood were studied. Thirty-seven patients had polyarticular onset, nine pauciarticular onset, and two systemic onset disease. The age of onset ranged from two to 15 years, with a median age of $9 \cdot 4$ years. The onset of disease was between ages two and five years for 13 patients, between six and 10 years for nine patients, and between 11 and 15 years for 26 patients. The average age of the patients when last studied was 25.3 years. The duration of the disease when tested after the age of 17 years ranged from five to 31 years, with a mean duration of $16 \cdot 5$ years.

Forty-eight patients were evaluated over a 10 -year period. Seven patients $(15 \%)$ were positive for RF detected by the LFT, with titres ranging from 1:40 to 1:5120. The serum was positive (titre $>1: 16$ ) for RF detected by haemolytic assay in 12 cases $(25 \%)$. Five patients were positive for 19S IgM RF detected by both tests; the titres determined by the LFT were higher in all five patients. Hidden 19S IgM RF $(>1: 16)$ were found on at least one assessment in 32 patients $(67 \%)$ and correlated well with fluctuations in disease activity. Overall, in 88 serum samples evaluated in the 48 patients disease activity correlated with IgM hidden RF titres in 55/88 (62\%). Twenty-one patients were evaluated before and after their 17th birthday. Hidden RF persisted in seven and remained negative in two. Five patients were positive before the age of 17 years and negative when tested after 17. Four patients were negative before the age of 17 years and positive after 17 .

ANA were present in 22 of 48 patients $(46 \%)$ with titres ranging from $1: 40$ to $1: 1600$. Twelve $(54 \%)$ had a speckled pattern and $10(46 \%)$ a diffuse pattern.

Control studies for hidden 19S IgM RF were performed on 35 healthy children ages one to 16 
296. Speiser, Moore, Weiss, Baldassare, Ross, Osborn, Dorner, Zuckner

Table 1 Summary of clinical and laboratory data of adults with juvenile rheumatoid arthritis onset

\begin{tabular}{|c|c|c|c|c|c|c|c|c|}
\hline Patient & Sex & $\begin{array}{l}\text { Age of } \\
\text { onset } \\
\text { (years) }\end{array}$ & $\begin{array}{l}\text { Current } \\
\text { age }\end{array}$ & $\begin{array}{l}\text { Type of } \\
\text { onset }\end{array}$ & $\begin{array}{l}\text { Serum } \\
R F \\
(L F T)^{*}\end{array}$ & $\begin{array}{l}\text { Serum } \\
R F \\
(H A)^{+}\end{array}$ & $\begin{array}{l}\text { Hidden } R F \\
\text { (IgM fraction) } \\
(H A) \ddagger\end{array}$ & $A N A \S$ \\
\hline 1 & $\mathrm{~F}$ & 11 & 23 & $\mathrm{~Pa}^{\|}$ & Neg. & $1: 4$ & $1: 4$ & Neg. \\
\hline 2 & $\mathbf{F}$ & 2 & 21 & $\mathrm{~Pa}$ & Neg. & $1: 8$ & $1: 64$ & $1: 320, \mathrm{~S}$ \\
\hline 3 & $\mathrm{~F}$ & 6 & 21 & Po' & Neg. & $1: 64$ & $1: 64$ & Neg. \\
\hline 4 & M & 12 & 38 & Po & Neg. & $1: 8$ & $1: 4$ & Neg. \\
\hline 5 & $F$ & 7 & 30 & Po & Neg. & $1: 4$ & $1: 2$ & $1: 20, \mathrm{D}$ \\
\hline 6 & $\mathrm{~F}$ & 13 & 19 & Po & $1: 5120$ & $1: 512$ & $1: 1024$ & $1: 640, \mathrm{~S}$ \\
\hline 7 & $\mathrm{~F}$ & 11 & 25 & Po & Neg. & $1: 512$ & $1: 1024$ & $1: 40, \mathrm{~S}$ \\
\hline 8 & $\mathrm{~F}$ & 9 & 21 & Po & Neg. & $1: 8$ & $1: 32$ & Neg. \\
\hline 9 & $F$ & 2 & 24 & $\mathrm{~Pa}$ & Neg. & $1: 32$ & $1: 128$ & $1: 400, \mathrm{D}$ \\
\hline 10 & $\mathbf{F}$ & 6 & 23 & Po & Neg. & $1: 16$ & $1: 256$ & $1: 160, \mathrm{~S}$ \\
\hline 11 & $\mathrm{~F}$ & 10 & 18 & Po & Neg. & $1: 4$ & Neg. & $1: 640 . \mathrm{S}$ \\
\hline 12 & M & 9 & 30 & Po & Neg. & $1: 4$ & $1: 128$ & Neg. \\
\hline 13 & $F$ & 2 & 26 & Po & Neg. & $1: 8$ & $1: 8$ & $1: 64, \mathrm{~S}$ \\
\hline 14 & $\mathrm{~F}$ & 11 & 29 & Po & $1: 5120$ & $1: 64$ & $1: 512$ & $1: 520, \mathrm{~S}$ \\
\hline 15 & $\mathrm{~F}$ & 13 & 23 & $S y^{* *}$ & Neg. & $1: 16$ & $1: 128$ & Neg. \\
\hline 16 & $\mathrm{~F}$ & 2 & 19 & Po & Neg. & $1: 64$ & $1: 64$ & $1: 40, \mathrm{~S}$ \\
\hline 17 & $\mathrm{~F}$ & 15 & 37 & Po & $1: 640$ & $1: 128$ & $1: 32$ & 1:100, D \\
\hline 18 & $\mathrm{~F}$ & 13 & 28 & Po & $1: 40$ & $1: 4$ & $1: 32$ & Neg. \\
\hline 19 & $\mathrm{~F}$ & 15 & 25 & Po & Neg. & $1: 16$ & $1: 32$ & Neg. \\
\hline 20 & $\mathrm{~F}$ & 4 & 34 & Sy & Neg. & $1: 512$ & $1: 64$ & Neg. \\
\hline 21 & $\mathrm{~F}$ & 3 & 20 & $\mathrm{~Pa}$ & Neg. & $1: 16$ & $1: 16$ & Neg. \\
\hline 22 & $F$ & 12 & 23 & Po & Neg. & $1: 8$ & $1: 64$ & $1: 200 . \mathrm{D}$ \\
\hline 23 & $\mathrm{~F}$ & 5 & 30 & Po & Neg. & $1: 32$ & $1: 64$ & Neg. \\
\hline 24 & $\mathrm{~F}$ & 13 & 36 & Po & Neg. & Neg. & $1: 2$ & Neg. \\
\hline 25 & $\mathbf{M}$ & 11 & 20 & Po & Neg. & $1: 8$ & $1: 128$ & Neg. \\
\hline 26 & $\mathrm{~F}$ & 15 & 31 & Po & Neg. & Neg. & $1: 16$ & $1: 20, \mathrm{D}$ \\
\hline 27 & $F$ & 15 & 26 & Po & Neg. & Neg. & Neg. & Neg. \\
\hline 28 & $\mathbf{M}$ & 12 & 31 & Po & Neg. & $1: 4$ & $1: 64$ & Neg. \\
\hline 29 & $\mathrm{~F}$ & 5 & 33 & Po & Neg. & $1: 8$ & Neg. & Neg. \\
\hline 30 & $\mathbf{F}$ & 15 & 24 & Po & Neg. & Neg. & $1: 64$ & Neg. \\
\hline 31 & $\mathrm{~F}$ & 15 & 32 & Po & $1: 5120$ & $1: 512$ & $1: 1024$ & $1: 100, \mathrm{D}$ \\
\hline 32 & $F$ & 12 & 27 & Po & Neg. & $1: 8$ & $1: 32$ & Neg. \\
\hline 33 & $\mathbf{F}$ & 7 & 37 & Po & Neg. & $1: 8$ & $1: 32$ & $1: 200, \mathrm{D}$ \\
\hline 34 & $F$ & 11 & 31 & Po & Neg. & $1: 8$ & $1: 32$ & Neg. \\
\hline 35 & $\mathbf{F}$ & 11 & 32 & Po & Neg. & $1: 16$ & $1: 16$ & Neg. \\
\hline 36 & $\mathbf{F}$ & 13 & 22 & Po & Neg. & $1: 8$ & $1: 32$ & Neg. \\
\hline 37 & $F$ & 7 & 34 & Po & $1: 160$ & $1: 16$ & $1: 32$ & $1: 80 . \mathrm{D}$ \\
\hline 38 & $\mathrm{~F}$ & 15 & 21 & Po & Neg. & Neg. & Neg. & $1: 640, \mathrm{~S}$ \\
\hline 39 & $F$ & 14 & 19 & $\mathrm{~Pa}$ & Neg. & $1: 8$ & $1: 16$ & $1: 20, \mathrm{~S}$ \\
\hline 40 & $\mathrm{~F}$ & 10 & 18 & $\mathrm{~Pa}$ & Neg. & $1: 16$ & $1: 64$ & $1: 80, \mathrm{~S}$ \\
\hline 41 & $\mathrm{~F}$ & 5 & 25 & Po & Neg. & $1: 4$ & $1: 512$ & $1: 80, \mathrm{D}$ \\
\hline 42 & $F$ & 13 & 28 & Po & Neg. & $1: 2$ & $1: 64$ & $1: 80, \mathrm{D}$ \\
\hline 43 & $\mathrm{~F}$ & 4 & 20 & Po & Neg. & $1: 8$ & $1: 1024$ & Neg. \\
\hline 44 & $\mathrm{~F}$ & 2 & 20 & $\mathrm{~Pa}$ & Neg. & $1: 64$ & $1: 512$ & $1: 100, \mathrm{D}$ \\
\hline 45 & $\mathbf{M}$ & 11 & 18 & Po & Neg. & $1: 8$ & Neg. & $1: 160, \mathrm{~S}$ \\
\hline 46 & $\mathrm{~F}$ & 11 & 21 & $\mathrm{~Pa}$ & Neg. & $1: 16$ & $1: 64$ & Neg. \\
\hline 47 & $\mathbf{M}$ & 2 & 19 & $\mathrm{~Pa}$ & Neg. & Neg. & $1: 16$ & $1: 160, \mathrm{~S}$ \\
\hline 48 & $F$ & 4 & 22 & Po & $1: 640$ & $1: 32$ & $1: 32$ & $1: 1600, \mathrm{D}$ \\
\hline
\end{tabular}

$\ddagger$ Hidden 19S IgM rheumatoid factor (RF) in IgM fraction as detected by haemolytic assay (HA) (titre $>1: 16$ considered positive). \$Antinuclear antibody (ANA), diffuse (D) or speckled (S) pattern.

$\|$ Pauciarticular $(\mathrm{Pa})$ onset type juvenile rheumatoid arthritis.

IPolyarticular ( $\mathrm{Po}$ ) onset type juvenile rheumatoid arthritis.

${ }^{* *}$ Systemic (Sy) onset type juvenile rheumatoid arthritis.

years, 25 healthy adults ages 17 to 40 years, 30 CTD patients ages one to 16 years and 25 CTD controls ages 17 to 40 years. The 35 healthy children showed a median hidden RF titre of $1: 7$ by the haemolytic assay, the 30 CTD controls in this age group 1:5, the
25 healthy adults $1: 6$, and the 25 adults with CTD $1: 5$. The combined controls of these 115 patient $\$$ showed an overall median titre of 1:6. We, there $\Phi_{0}$ fore, considered that two standard deviations above the median titre (titres $>1: 16$ ) were significant. ${ }^{5}$ 


\section{Discussion}

Allen and $\mathrm{Kunkel}^{3}$ had shown that hidden IgM RF with agglutinating ability were present in the serum of a small number of adults with seronegative RA, but Robbins and Moore, ${ }^{10}$ on the contrary, were not able to detect complement-fixing hidden IgM RF in adult seronegative RA patients. Complement-fixing hidden IgM RF had previously been detected in the majority of children with seronegative JRA. ${ }^{4-7}$

In this study complement-fixing hidden $19 \mathrm{~S}$ IgM $\mathrm{RF}$ were found in adult patients with JRA onset in $67 \%(32 / 48)$ of cases, results similar to those $(59-68 \%)$ previously noted in children with JRA. ${ }^{5} 6$ Complement-fixing hidden RF titres correlated with disease activity in $62 \%(55 / 88)$ of instances, a lower incidence than that found in children with JRA where there was a $92 \%(93 / 101)$ correlation. ${ }^{7}$ In these patients the percentage of hidden RF $(67 \%)$ was greater than that of ANA (46\%), positive serum RF determined by the haemolytic assay $(25 \%)$, or by the LFT $(12 \%){ }^{7}$

Thirty patients $(62 \%)$ had active disease when examined as adults, but only $12(25 \%)$ had severe, erosive disease. Nineteen of 30 patients with active disease were either currently being treated with or had previously received 'remission inducing' or immunosuppressive agents, such as, gold salts, D-penicillamine, methotrexate, or azathioprine. Of 18 patients with inactive disease seven were previously treated with gold salts and five were continuing on maintenance gold therapy; 13 patients had remained on non-steroidal anti-inflammatory drugs. Of 31 patients who received 'remission inducing' agents $27(87 \%)$ initially had positive hidden RF; four of these subsequently became hidden RF negative, while 23 continued to show positive hidden RF. There was no reduction in titres of hidden RF in these patients.

The presence of RF determined by LFT correlated with the age of onset of JRA. Hanson et al. ${ }^{11}$ showed a rise in the incidence of RF determined by the LFT from $3.8 \%$ up to the age of four years, to $25 \%$ between four and 12 years, and to $77 \%$ at ages 12 to 16 years. In our patients only one of 13 children with onset of disease up to five years of age was positive for RF determined by the LFT, but eight were positive for IgM hidden RF. In the six- to 10-year-old onset group one of nine had a positive LFT for RF, but seven had a positive test for IgM hidden RF. For those with onset at 11 to 15 five of 26 were seropositive by LFT and 17 of 26 had a positive test for IgM hidden RF. The presence of hidden RF in the child with JRA therefore did not change significantly with age. Jeremy et al. ${ }^{12}$ looked at the incidence of RF in patients with JRA whose disease had persisted into adulthood. They found no correlation between the presence of RF as detected by LFT and duration or severity of the disease. In our study in the age group 17 to 25 years hidden RF were found in 20 of 27 patients, at 26- to 30-years old in six of nine patients, and above 31 years in six of 12 cases. There was no significant reduction in hidden RF positivity with age. Overall, 19S IgM RF seemed independent of age of onset in the JRA onset group and did not change significantly in young adulthood. There was also no change related to duration of disease.

Hidden RF have been demonstrated in all three onset types of JRA but more frequently in the polyarticular onset group. ${ }^{56}$ This group most frequently has long-term disease activity. ${ }^{1}{ }^{1}{ }^{13}$ Thirtyseven of 48 patients in this study had a polyarticular onset, 26 of whom had raised titres of hidden RF at one time during the course of their disease.

Although the pathogenic role for IgM RF and hidden IgM RF in JRA has not been completely understood, the correlation of hidden RF with disease activity and with polyarticular onset disease and its resultant higher incidence of a chronic and more severe illness strongly suggests a pathogenic role for hidden 19S IgM RF in JRA. This potential has also been suggested by studies that showed the presence of 19S IgM RF and hidden 19S IgM RF in immune complexes in these patients. ${ }^{14} 15$

In conclusion complement-fixing hidden 19S IgM RF were shown to be present in the majority of seronegative adult arthritis patients with childhood onset JRA. The presence of hidden RF correlated with disease activity. In contrast, previous studies on seronegative adult onset RA patients showed no evidence of complement-fixing hidden 19S IgM RF in these patients. ${ }^{10}$ These studies suggest that patients with seronegative JRA onset may have different pathophysiological mechanisms of disease than patients with adult onset seronegative RA.

Supported in part by a grant from the NIH, a Research Career Development Award from the NIADDK (Dr Moore) (AM-036), and grants from the Easter Seal Research Foundation, Flcur de Lis Foundation of St Louis, Eastern Missouri Chapter of The Arthritis Foundation, and the McDonnell-Douglas Corporation of St Louis.

\section{References}

1 Schaller J. Juvenile rheumatoid arthritis: series 1. Arthritis Rheum 1977; 20 (suppl): 165-70.

2 Johnson $\mathbf{P}$ M, Faulk W P. Rheumatoid factor: its nature, specificity, and production in rheumatoid arthritis. Clin Immunol Immunopathol 1976; 6: 414-30.

3 Allen J C, Kunkel H G. Hidden rheumatoid factors with specificity for native gamma globulins. Arthritis Rheum 1966; 9: $759-68$. 
4 Moore T L, Dorner R W, Zuckner J. Hidden rheumatoid factor in seronegative juvenile rheumatoid arthritis. Ann Rheum Dis 1974: 33: 255-7.

5 Moore T L, Zuckner J. Baldassare A R. Weiss T D, Dorner $\mathrm{R} \mathrm{W}$. Complement-fixing hidden rheumatoid factor in juvenile rheumatoid arthritis. Arthritis Rheum 1978; 21: 935-41.

6 Moore T L. Dorner R W. Weiss T D. Baldassare A R. Zuckner J. 19S IgM hidden rheumatoid factor in juvenile rheumatoid arthritis. Pediatr Res 1980; 14: 1135-8.

7 Moore T L, Dorner R W, Sheridan P W, et al. Longitudinal study of the presence of hidden 19S IgM rheumatoid factor in juvenile rheumatoid arthritis. J Rheumatol 1982; 9: 599-602.

8 Brewer E J, Bass J. Baum J, et al. Current proposed revision of JRA criteria. JRA Criteria Subcommittee of the Diagnostic and Therapeutic Criteria Committee of the American Rheumatism Section of The Arthritis Foundation. Arthritis Rheum 1977; 20: 195-9.

9 Singer J M, Plotz C M. The latex fixation test. I. Application to the serologic diagnosis of rheumatoid arthritis. Am J Med 1956; 21 : 888-92.
10 Robbins D L. Moore T L. Lack of hidden complement-fixing IgM믐 rheumatoid factor in adult seronegative rheumatoid arthritis. $A n n ?$ ? Rheum Dis 1980; 39: 64-7.

11 Hanson V. Drexler E. Kornreich H. The relationship of rheumatoid factor to age of onset in juvenile rheumatoid arthritis 0 Arthritis Rheum 1969; 12: 82-6.

12 Jeremy R. Schaller J, Arkless R. Wedgwood R J. Healey L A. Juvenile rheumatoid arthritis persisting into adulthood. AmJ Med $1968 ; 45: 419-34$.

13 Hanson V. Kornreich H. Bernstein B. Prognosis of juvenileav rheumatoid arthritis. Arthritis Rheum 1977; 20 (suppl): 279-84. क

14 Moore T L. Sheridan P W, Zuckner J, Dorner R W. Separation $\overrightarrow{0}$ and characterization of immune complexes containing $19 \mathrm{~S} \operatorname{IgM}$ rheumatoid factor-IgG in juvenile arthritis. Arthritis Rheum $1983 \vec{\omega}$ 26: 165-9.

15 Moore T L, Dorner R W, Sheridan P W, Zuckner J. Precipitation of 19S IgM rheumatoid factor-IgG circulating immune complexes@ in patients with juvenile arthritis by polyethylene glycol and separation by immobilized protein A. Clin Exp Immunol 1984;56: 247-52. 